\title{
Cost analysis of blood purification: a tool for decision-making and supply chain optimization
}

\author{
Silvia Grazzini ${ }^{1}$, Claudia Razzauti ${ }^{1}$, Lea Paola Fabbri ${ }^{2 *}$, Michele Galatà ${ }^{3}$, Stefano Bellucci ${ }^{4}$, Ilaria Colivicchi ${ }^{5}$ and \\ Maria Elvira Mancino ${ }^{5}$
}

\begin{abstract}
This study complies with the reorganization of health care provider processes based on the cost of life cycle of the product. The aim is to determine the costs of treatment administration of extracorporeal dialysis and other treatments in extracorporeal systems.

The strategy here was to apply for the first time the "bill of material" (BoM) method to the production and management of the services above.

By using standard replacement flows, we build the "bill of materials" to calculate the cost of a CRRT (continuous renal replacement therapy) with anticoagulant. The standard cost of the process is thus obtained.

The method here developed can be used for accounting purposes and for economic planning, as a tool for accurate statistical evaluation of medical care.
\end{abstract}

Keywords: Bill of materials, Continuous renal replacement therapy, Regional anticoagulation, Citrate, Cost of life cycle

\section{Introduction}

This paper provides a method to determine the costs of treatment administration of extracorporeal dialysis and other treatments in extracorporeal systems, from a citrate CRRT treatment, proposed by the industry, and from another regional anticoagulation realized using heparin, protamine hydrochloride, and epoprostenol previously reported by Fabbri et al. [1], and here called HPE. The two methods are comparable because the anticoagulant strategy is limited to the extracorporeal circuit (regional anticoagulation), representing a key issue for safe and effective RRT (renal replacement therapy). HPE and similar (without citrate) methods were recently reviewed by Brophy et al. [2], by considering benefits and drawbacks, including circuit lifespan. The anticoagulant allows to easily reach the target of $72 \mathrm{~h}$ of treatment as explained by the device technical documentation.

In this context, the present study allows one to thoroughly address a budget target concerning the monitoring of overall expenditure for procurement and management

* Correspondence: lea.fabbri@libero.it

${ }^{2}$ Independent Researcher, Pistoia, Italy

Full list of author information is available at the end of the article decisions. In this way, the study can provide a guideline to calculate the life-cycle costs of the product, in agreement with the European legislation about public procurement, see [3]. Health system public procurement is generally based on the economically most advantageous tender. On the other hand, for the recent European directive, see [3], a new criterion was introduced based on the life-cycle cost as it considers also environmental and/or social aspects. In our study, we proved that three equivalent techniques imply different overall costs in terms of circuit life, waste management, personnel costs, etc.

Cost analysis starts when the machine is ready for usage with the appropriate medical devices and stops at waste management.

In the literature, several studies have developed cost analysis related to such treatments, starting from the cost of consumables and human resources required for their administration (see, e.g., [4]). The costs are calculated with time references differing from study to study. Fluid, dialysate, and reinfusion liquid consumption are usually calculated taking into account average flows, while the variability of the reinfusion liquid flows upon varying solute concentration is neglected. 
On the other hand, some analyses, like [5], demonstrate that flows are actually extremely variable, fact that determines a high-cost variability, which is also due to different work organization. Other studies focus on the trend of the human resource costs, which vary considerably with work organization and treatment administration procedure (see, e.g., [6]).

Hence, it follows that the results of the various studies are hardly comparable among themselves since the difficulty of accurately identify the real contribution of each raw material to the treatments remains. Indeed, to the very best of our knowledge, the standard cost of such treatments has never been calculated so far. For this reason, it is not possible to make a factual comparison between the prices of the treatments as a whole, but it is only possible to make a comparison between single parts.

The economic crisis of the last 10 years has led us to take into account not only the clinical outcome, but also the economic one, especially in treating patients of the critic care, whose cost represents one of the most relevant items of expenditure in the health sector, as in [7]. The literature shows that also QALYs (Quality-Adjusted Life Year) studies (see, e.g., [8, 9]) must not disregard a thorough cost analysis and a research of production processes that are able to reduce them, so that the choice of the methodology may go back to being primarily of clinical type, as in [10-12].

The purpose of the present paper is to provide a method for analyzing standard costs correlated to the product life cycle, i.e., of treatment administration, according to [3]. The use of citrate as an anticoagulant has been wide-spreading since 2010, it can be used as a base for a number of other treatments but its cost depends on several variables which make it difficult to determine with acceptable accuracy.

\section{Materials and methods}

\section{Description of materials used}

All the materials are referred to 2015 technology. The following materials are employed for the entire treatment:

1) Infusion bags and dialysate: 5 - $\mathrm{L}$ bags including all formulations on the market at the same price range. The dialysate bags are without calcium.

2) Bags with $10 \mathrm{~L}$ effluent for the citrate system with a flow equal to $200 \mathrm{~mL} / \mathrm{h}$-bags with $9 \mathrm{~L}$ effluent for citrate system with a flow equal to $2250 \mathrm{~mL} / \mathrm{h}$ : for the calculation of costs, the average price among those of the purchase procedure is used.

3) 2-L bags with citrate concentration of $136 \mathrm{mmol}$ $\mathrm{Na}_{3} / \mathrm{L}$ for the system citrate flow equal to 200 $\mathrm{mL} / \mathrm{h}-5 \mathrm{~L}$ citrate bags with a concentration of $12 \mathrm{mmol} \mathrm{Na}_{3} / \mathrm{L}$ for the citrate system with a flow equal to $2250 \mathrm{~mL} / \mathrm{h}$ : for the calculation of costs the average price among those of the purchase procedure is used.

4) HPE: replacement bags and dialysate bags $5 \mathrm{~L}$; effluent bags $10 \mathrm{~L}$; heparin 25,000 I.U./5 mL vial; protamine hydrochloride $50 \mathrm{mg} / 5 \mathrm{~mL}$ vial at the dosage of $1 \mathrm{mg} / 100$ I.U. Heparin; epoprostenol 0.5 $\mathrm{mg}$ plus $50 \mathrm{~mL}$ diluent

5) Kit with lines, filter, junctions (joints, fittings): for the calculation of costs, the average price among those of the purchase procedure is used.

6) Monitors in usage.

\section{Model description}

In order to calculate the actual cost of each treatment, we used the method of BoM (bill of materials) to identify all the components, sub or intermediate assemblies, raw materials, parts, and quantities of what is needed to carry out the treatment, determining the impact for each of them in the production process.

We built the BoM of a treatment in CRRT with citrate in CVVHDF (continuous venovenous hemodiafiltration) mode, proposed by the industry, and in CRRT with heparin, protamine, and epoprostenol in CVVHDF mode. We assume, as usual, the examined treatment at zero level, and at least the most important components at level 1.

We can build simpler basic bills or more complex ones for the analysis of the most appropriate cost.

Determining the flows of substitution allows one to calculate the duration in minutes of each bag/vial used and, as a consequence, the number of bags/vials required to produce the considered treatment, compared to the duration of the treatment itself.

Flow replacements are parametrized using the ones most frequently programmed in the dialysis monitor. We call them "standard flows" following [13-15], and the related costs "standard costs."

In Table 1, we report the values for the treatment with citrate and the same values are shown for the HPE method.

Table 1 Prescribed dose for a treatment in CRRT in CWHDF mode with anticoagulant

\begin{tabular}{lll}
\hline FLOW & DESCRIPTION & CWHDF \\
\hline Qb & Blood flow & $150 \mathrm{~mL} / \mathrm{min}$ \\
$\mathrm{Cp}$ & Weight loss & $100 \mathrm{~mL} / \mathrm{h}$ \\
$\mathrm{Qd}$ & Dialysate flow & $1300 \mathrm{~mL} / \mathrm{h}$ \\
Qinf & Replacement fluid flow (pre-post) & $2000 \mathrm{~mL} / \mathrm{h}$ \\
Qef & Effluent flow & $3400 \mathrm{~mL} / \mathrm{h}$ \\
$\mathrm{QNa}_{3}$ & Citrate flow $\mathrm{mL} / \mathrm{h}$ & To be determined \\
Qe & Heparin diluted flow & $1000 \mathrm{Ul} / \mathrm{h}$ \\
Qpr & Protamine diluted flow & $10 \mathrm{mg} / \mathrm{h}$ \\
Qp & Prostacyclin diluted flow (epoprostenol) & $20,000 \mathrm{ng} / \mathrm{h}$ \\
\hline
\end{tabular}


For the flow of fluids during CRRT treatments, a number of variables must be taken into account, related to the use of the therapeutic dose established by the operator according to the different types of patient. To this regard, we must consider that the prescribed dose can vary from 20 to 35 up to $43 \mathrm{~mL} / \mathrm{kg} / \mathrm{h}$ of effluent representing any exchange of fluids and the weight loss set. The dose, however, should never be less than $35 \mathrm{~mL} /$ $\mathrm{kg} /$ day, whichever mode you choose, CVVHD (continuous venovenous hemodialysis), $\mathrm{CVVH}$ (continuous venovenous hemofiltration), CVVHDF dividing the infusion rate in pre-and post-dilution as required by the operator based on the type of patient. When using the therapeutic dose of $43 \mathrm{~mL} / \mathrm{kg} / \mathrm{h}$, in the more complex form of CRRT, the CVVHDF, the portions of infusion fluids are generally distributed as follows: $25 \mathrm{~mL} / \mathrm{kg} / \mathrm{h}$ for the fluids to re-infusion and $18 \mathrm{~mL} / \mathrm{kg} / \mathrm{h}$ for the dialysate. Even for the lower doses, the ratio between convective and diffusive portion is about 60/40.

It should be noted, however, that there must be a verification of the dose prescribed and that actually provided. In theory, if there were no errors or changes the value of the effluent measured by the monitor should match that one expected. In fact, during the CRRT, there is always downtime related to the operations of the nursing staff estimated in the table of costs in $72 \mathrm{~h}$.

When the Qef value is used, as defined in Table 1, the citrate flow variable must be added, once it is determined.

The amount of citrate to be infused is assumed equal to $3 \mathrm{mmolNa}_{3} / \mathrm{L}$ of blood.

Once blood flow is established and given the concentration of citrate bag expressed in mmol $\mathrm{Na}_{3} / \mathrm{L}$, the citrate flow is determined by the linear relationship:

Qb mL/h: n. mmol di $\mathrm{Na}_{3} / \mathrm{L} / \mathrm{h}=\mathrm{Q} \mathrm{Na}$ mL/h: $3 \mathrm{mmol}$ $\mathrm{Na}_{3} / \mathrm{L} / \mathrm{h}$.

The industry proposes 2 -L bags with a concentration equal to $136 \mathrm{mmol} \mathrm{Na}_{3} / \mathrm{L}$ and $5 \mathrm{~L}$ bags with concentration equal to $12 \mathrm{mmol} \mathrm{Na}_{3} / \mathrm{L} / \mathrm{h}$.

The proportion determines a value of $\mathrm{QNa}_{3}$ equal to $200 \mathrm{~mL} / \mathrm{h}$ in the former case, and a value of $\mathrm{QNa}_{3}$ equal to $2250 \mathrm{~mL} / \mathrm{h}$, in the latter.

The total Qef therefore will vary from Qef $=3600 \mathrm{~mL} /$ h to Qef $=5650 \mathrm{~mL} / \mathrm{h}$ :

Qef $+\mathrm{QNa}_{3}=200 \mathrm{~mL} / \mathrm{h}$ (with Qef $=3600 \mathrm{~mL} / \mathrm{h}$ )

Qef $+\mathrm{QNa}_{3}=2250 \mathrm{~mL} / \mathrm{h}$ (with Qef $=5650 \mathrm{~mL} / \mathrm{h}$ )

We are now able to compute the coefficients of use of the bags or vials for $24 \mathrm{~h}$ and then for $72 \mathrm{~h}$ of treatment (Table 2).

The coefficients to use for medical devices for $72 \mathrm{~h}$ are equal to one unit each, for all types of considered treatment.

The coefficients needed for the equipment can be calculated, for all the different types of considered treatments, on the basis of the estimate of the average number of treatments performed each year. The following formula was used:

$C=(V / 8) / N$

where $C$ is the equipment cost for each treatment, $V$ is the market value of the equipment offered in the tender, to be amortized over 8 years, ${ }^{1} N$ is the number of treatments/year per equipment. The coefficient of utilization of the monitor is $V / 8 N$. $V$ includes the cost of maintenance and technical assistance. Regarding the cleaning of the circuit, this is carried out before each treatment with a washing solution in the extracorporeal blood circuit 2-L bag.

Electricity consumption is estimated by the equipment's service manual. Unit costs of electric power and wastes were taken from the power supply and waste disposal contracts, respectively valid at the time of the present study. Staff and laboratory tests costs were provided by the management control system of health authorities. Average unit costs were determined by the management control system according to costs analytical accounting.

Among the coefficients related to the management of the process, for all the types of the considered treatment, the interventions of personnel for the exchange-bags/ vials, is estimated equal to $5 \mathrm{~min}$, plus additional $5 \mathrm{~min}$ for each laboratory test. During the treatments proposed by the industry, an average of 14 laboratory tests are performed: these are tests of blood gas analysis, performed at the beginning of the treatment, after $5 \mathrm{~min}$, after $3 \mathrm{~h}$ and then one every $6 \mathrm{~h}$. During all the types of treatments in HPE, an average of four laboratory tests are performed: these are complete coagulation tests.

The amount of liquid waste is given by the remainder in the infusion bags, dialysate, citrate if infused, plus replacement fluids consisting of the decrease in weight of $7.2 \mathrm{~L}$ in $72 \mathrm{~h}$. In case of a $\mathrm{QNa}_{3}=200 \mathrm{~mL} / \mathrm{h}$ treatment, the replacement fluid is $260 \mathrm{~L}$ (actually, $93.9 \mathrm{~L}+144 \mathrm{~L}+$ 14.4 L + 7.2 L = 259.5 L).

This is likely due to approximations of calculation. The error, however, is believed to be negligible. The same applies to the $\mathrm{QNa}_{3}=2250 \mathrm{~mL} / \mathrm{h}$ treatment, for which the calculated discrepancy is equal to $720 \mathrm{~mL}$ in $72 \mathrm{~h}$.

The solid wastes were weighed at the end of each type of treatment: $100 \mathrm{~g}$ for empty 5 - $\mathrm{L}$ bag and $200 \mathrm{~g}$ for empty 9 or $10-\mathrm{L}$ bag; the empty kit for the $\mathrm{QNa}_{3}=$ $200 \mathrm{~mL} / \mathrm{h}$ treatment is $1.600 \mathrm{~kg}$, and $1.150 \mathrm{~kg}$ for the $\mathrm{QNa}_{3}=2250 \mathrm{~mL} / \mathrm{h}$ treatment.

In CRRT in CVVHDF mode with HPE, anticoagulant-related wastes are not present.

\section{Results}

The standard costs can be calculated using the contract prices, noted by the sign " $€$ ". ${ }^{2}$ Electric power supply cost is estimated to be $0.17 € / \mathrm{KW}$. Personnel 
Table 2 Number of bags per $24 \mathrm{~h}$ treatments CRRT in CWHDF mode with citrate and with HPE

\begin{tabular}{|c|c|c|c|}
\hline Treatments in CWHDF with anticoagulant & Utilized components & $\begin{array}{l}\text { Minute duration bags or vials } \\
\text { (bag's volume/infusion flow) }\end{array}$ & Bags per $24 \mathrm{~h}$ \\
\hline & Dialysate bags without Ca $5 \mathrm{~L}$ & $230 \mathrm{~min}$ & ก. 6.26 \\
\hline & Replacement bags $5 \mathrm{~L}$ & $150 \min$ & ก. 9.6 \\
\hline & $\mathrm{Na}_{3}$ bags $2 \mathrm{~L}$ with $136 \mathrm{mmol} \mathrm{Na} / \mathrm{L}$ & $600 \min$ & n. 2.4 \\
\hline & $\mathrm{Na}_{3}$ bags $5 \mathrm{~L}$ with $12 \mathrm{mmol} \mathrm{Na} / \mathrm{L}$ & $132 \mathrm{~min}$ & n. 10.9 \\
\hline & Effluent bags at Qef $=5650 \mathrm{~mL} / \mathrm{h}$ & $95 \mathrm{~min}$ & n. 15.16 \\
\hline & Effluent bags at Qef $=3600 \mathrm{~mL} / \mathrm{h}$ & $166 \min$ & n. 8.67 \\
\hline & Heparin vial $25,000 \mathrm{UI}$ & 1500 min & n. 0.96 \\
\hline & Protamine vial $250 \mathrm{mg}$ & $1500 \mathrm{~min}$ & n. 4.8 \\
\hline & Epoprostenol prostacyclin vial 500,000 ng & $1500 \mathrm{~min}$ & n. 0.96 \\
\hline
\end{tabular}

cost has been estimated with the aid of the management control. It was calculated as the average cost comprehensive of allowance and related obligations, and resulted to be equal to $0.38 € / \mathrm{min}$. The cost of laboratory analyses is the same as calculated by the management control. Waste disposal costs are estimated to be $1.00 € / \mathrm{L}$ or $\mathrm{kg}$. The costs are summarized in Tables 3 and 4 .

The total costs of replacement fluids of medical devices and equipment are not significantly different for the three methods and therefore they can be considered constant in these three cases.

The cost difference between the two methodologies proposed by the industry is due to the number of citrate bags necessary for the treatment. Such variable in turn depends on solute concentration (citrate, in this case) with respect to the therapeutic dose. The solute concentration is an important variable that might be standardized (see [16]) with respect to the therapeutic doses in order to contribute to consumption and cost reduction.

In the case of HPE, the cost of the anticoagulant is related to the costs of the components used in the treatment.

Process costs are highly correlated to the different methods of regional anticoagulant.

This or a similar method should be applied to calculate the life-cycle costs, every time a medical device requires consumable material.

In order to extend the cost analysis, the major out-of-process parameters affecting the average/standard cost of the treatment were also taken into account. ${ }^{3}$

It is known that the lifetime of the filter has a major impact on the overall costs due to the possibility of filter clotting, which in turn determines further out-of-process costs which can be calculated thanks to the BoM. In fact, in such circumstance, the treatment has to be discontinued, patient taken off the machine, bags and filter disposed of the new circuit has to be assembled, washed with priming solution, and connected to the patient to resume the treatment.
Circuit lifetime was estimated from Gattas et al. [17] in the case of citrate and from Fabbri et al. [1] in the case of HPE.

From Kaplan-Meier estimate in [17], the probability $p=0.25$ for the circuit survival for the whole duration of the treatment $(72 \mathrm{~h})$ was inferred. In the case when no filter clotting occurs $(p=0.25)$ the citrate treatment cost, as calculated with the BoM, averaged over the two different infusion flow rates $\left(\mathrm{QNa}_{3}=2250 \mathrm{~mL}\right.$ and $\mathrm{QNa}_{3}=$ $200 \mathrm{~mL} / \mathrm{h}$ ), as proposed by the industry, is $C=1525.12 €$.

In the complementary clotting scenario, whose occurrence has probability $1-p=0.75$, out-of-process costs to be considered are 1 dialysate bag, 1 replacement bag, $1 \mathrm{Na}_{3}$ bag, 1 effluent bag, 1 filter/equipment; costs of disposal of replaced bags (this can be determined only when knowing the clotting time $\mathrm{t}$ ); personnel costs, $50 \mathrm{~min}$.

Considering the above extra-costs, the total outof-process costs: $C_{\mathrm{OoP}}=174.38 €$. Therefore, the cost increases by $11.4 \%$.

In total, the overall mean value cost weighted on the two scenarios, according to the given probability $p$, is equal to

$$
p \cdot C+(1-p) \cdot\left(C+C_{\mathrm{OoP}}\right)=1655.90 €
$$

Considering instead HPE treatment, we have, according to [1], that the probability for the circuit survival for the whole duration of the treatment is $p=0.40$. We have $C=1270.82 €$, with a total out-of-process costs $C_{\mathrm{OoP}}=160.46 €$, amounting to a cost increase of $12.6 \%$. Therefore, the overall mean value cost weighted on the two scenarios, according to the given probability $p$, is equal to

$$
p \cdot C+(1-p) \cdot\left(C+C_{\mathrm{OoP}}\right)=1367.10 €
$$

We developed dynamic spreadsheets to be filed for each patient, taking into account the actual flows and actual therapeutic doses, which may vary during $72 \mathrm{~h}$ of 


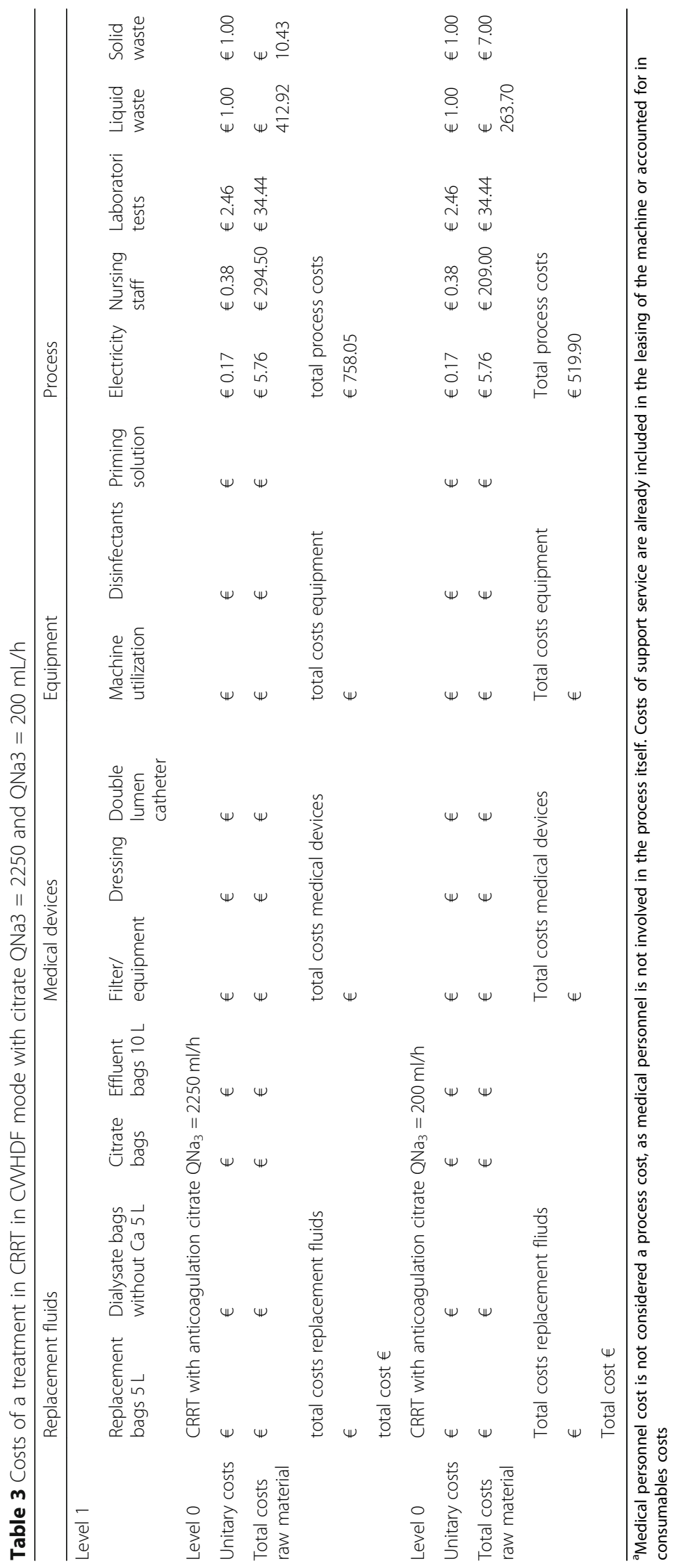




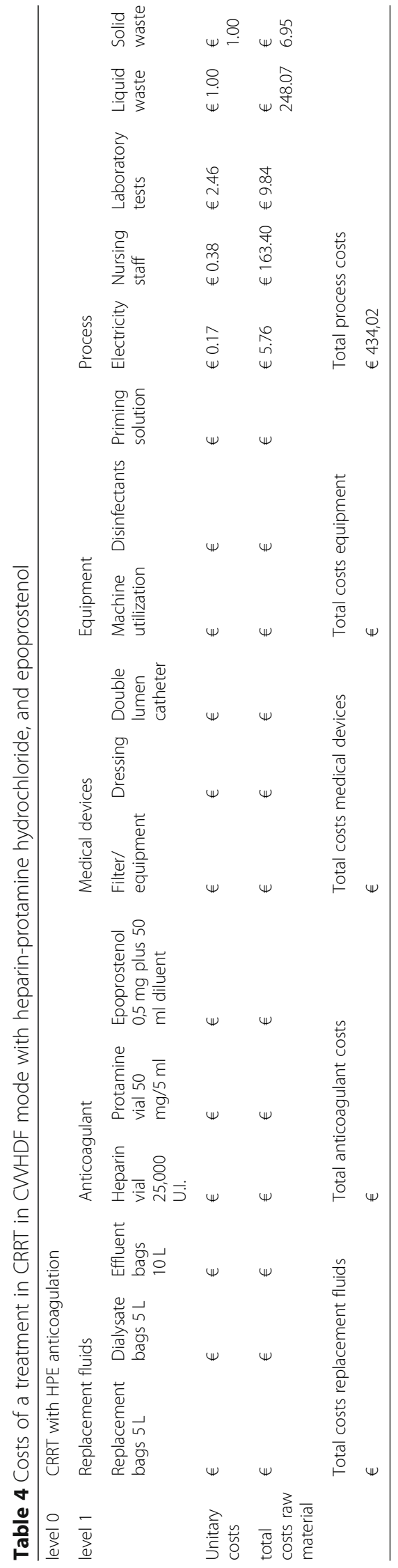


treatment. In this way, it is possible to accurately predict and calculate real-time consumption and the cost of the active productive process and collect the data needed to implement an appropriate statistical analysis.

\section{Discussion}

During the fulfillment of our contract, we submitted our BoMs to three suppliers; these BoMs were based on standard flows, taking into account only the consumables.

They were asked to determine the citrate flow starting from the therapeutic infusion dose, $3 \mathrm{mmol} \mathrm{QNa}_{3} /$ blood/L. The suppliers are therefore taking part in the expense control phase. Their answers were compared with our results. One supplier provided data in agreement with the ones expected for 7 methods out of 7 . Another supplier provided the data expected for 7 methods out of 9, and underestimated data for 2 methods: the mismatch is due to the fact that $\mathrm{QNa}_{3}$ values lower than actual ones were declared. The third supplier failed to provide any data for 2 methods out of 2 , stating that the costs were not determinable.

These results confirmed the correctness of the method. The method was however further checked by a medical-scientific and an engineering point of view. Moreover, further investigations concerning the production process discussed above were carried out. These deeper controls led us to conclusions that could not be drawn from the simpler BoM, submitted to suppliers. For instance, it can be inferred that in CRRT treatments with citrate, the concentration of the solution in the bag obviously importantly affects the quantity of the bags needed and therefore on personnel costs, the liquid waste produced and on the standard cost.

\section{Conclusion}

Precise identification of real contribution of each raw material to the treatments makes it possible to estimate exactly the cost of the product life cycle. Such transparency can guide the medical activity, as well as the choices of the industry and the public buyer. The clinicians may include in their choices considerations about personnel management, easiness, and readiness of laboratory analysis and waste disposal. Since the BoM takes into account all the costs detailed above, it may be an efficient tool to guide the internal activities of the suppliers who, in turn, may invest in research and development to obtain more efficient BoMs to submit to the public service [16]. Such types of analyses allow the suppliers to enter the process supply chain and take advantage of their own ability in competitive cost reduction.

The public buyer is able to predict, quantify, and justify higher than expected expenses.

Lastly, BoM provides a valuable tool for the assessment of the supply quality, quantifying qualitative aspects, otherwise difficult to measure and compare. In this way, determining standard costs would be an asset for all the health productive processes.

\section{Endnotes}

${ }^{1}$ At the time of the tender, Italian legislation established 8 years term as depreciation rate for electromedical devices, that is $12.5 \%$ per annum of the market value (Decreto Ministero dell'Economia e delle Finanze, 31 dicembre 1988).

${ }^{2}$ Detailed costs proposed by the industry are considered confidential data and therefore not fully disclosable.

${ }^{3}$ Unit costs of electric power, laboratory tests, and wastes are determined by long-term ( 10 years) contracts; therefore, they can be considered constant during the considered period. Staff contracts are renegotiated every 10 years.

${ }^{4}$ For simplicity, the adverse complementary scenario considers the occurrence of a single clotting.

\section{Abbreviations}

BoM: Bill of materials; CRRT: Continuous renal replacement therapy:

CWH: Continuous venovenous hemofiltration; CWHD: Continuous venovenous hemodialysis; CWHDF: Continuous venovenous hemodiafiltration; HPE: Heparin, protamine hydrochloride, epoprostenol; QALYs: Quality-adjusted life year;

RRT: Renal replacement therapy

\section{Acknowledgements}

Not applicable.

Funding

Not applicable.

\section{Availability of data and materials}

Data sharing not applicable to this article as no datasets were generated or analyzed during the current study. Please contact the corresponding author for data request.

\section{Authors' contributions}

SG and CR provided the implementation of the accountability method and the economic study. SB analyzed the process from an engineering and clinical point of view. LPF and MG studied all the medical issues to complete the cost analysis. MEM and IC contributed to the analysis and the interpretation of the data and assisted in the preparation of the manuscript. All authors read and approved the final manuscript.

Ethics approval and consent to participate Not applicable.

\section{Consent for publication}

Not applicable.

\section{Competing interests}

The authors declare that they have no competing interests.

\section{Publisher's Note}

Springer Nature remains neutral with regard to jurisdictional claims in published maps and institutional affiliations.

\section{Author details}

'Procurement Department of public assets and services, ESTAR Tuscany, Florence, Italy. Independent Researcher, Pistoia, Italy. ${ }^{3}$ Anaesthesia and Intensive Care Unit, Pontremoli Hospital, Massa Carrara, Italy. ${ }^{4}$ Clinical Engineering Department, ESTAR Tuscany, Florence, Italy. ${ }^{5}$ Department of Economics and Management, University of Florence, Florence, Italy. 
Received: 16 January 2019 Accepted: 7 May 2019

Published online: 27 June 2019

\section{References}

1. Fabbri LP, Nucera M, Al Malyan M, Becchi C. Regional anticoagulation and antiaggregation for $\mathrm{CWH}$ in critically ill patients: a prospective randomized, controlled pilot study. Acta Anesthesiol Scand. 2010;54:92-7.

2. Brophy P, Khan I, Deep A. Anticoagulation in CRRT. Chapter 17. In: Deep A, Goldstein SL, editors. Critical care nephrology and renal replacement therapy in children. Cham: Springer International Publishing AG, part of Springer Nature; 2018. p. 251-9.

3. Directive UE 2014/24/UE. 2014. https://eur-lex.europa.eu/homepage.html

4. Manns B, Doig CJ, Lee H, Dean S, Tonelli M, Johnson D, Donaldson C. Cost of acute renal failure requiring dialysis in the intensive care unit: clinical and resource implications of renal recovery. Crit Care Med. 2003:31(2):449-55.

5. Srisawat N, Lawsin L, Uchino S, Bellomo R, Kellum JA. Cost of acute renal replacement therapy in the intensive care unit: results from the beginning and ending supportive therapy for the kidney (BEST kidney) study. Crit Care. 2010;14(2):R46.

6. Vitale C, Bagnis C, Marangella M, Belloni G, Lupo M, Spina G, Bondonio P, Ramello A. Cost analysis of blood purification in intensive care units: continuous versus intermittent hemodiafiltration. J Nephrol. 2003;16:572-9.

7. Castellino S, Santoro D. Valutazione dei costi nelle terapie sostitutive renali in area critica. G Ital Nefrol. 2006;23, (Suppl 36:S139-42.

8. Ethgen O, Schneider AG, Bagshaw SM, Bellomo R, Kellum JA. Economics of dialysis dependence following renal replacement therapy for critically ill acute kidney injury patients. Nephrol Dial Transplant. 2015;30(1):54-61.

9. De Smedt DM, Elseviers MM, Lins RL, Annemans L. Economic evaluation of different treatment modalities in acute kidney injury. Nephrol Dial Transplant. 2012;27(11):4095-101.

10. Camporese A, Avolio M, Grosso S, Zigante P, Tosoni N, Diamante P, Lucchese T, De Rosa R, Stano P, Modolo ML. Lean Thinking, appropriatezza clinica e nuove tecnologie nel processo di miglioramento di efficienza ed efficacia della diagnostica delle malattie sessualmente trasmesse. Ital J Lab Med. 2013;9(3):170-5.

11. Nicosia, F.: Il nuovo ospedale è snello. Far funzionare gli ospedali con il Lean Healthcare: consigli pratici e sostenibilità. First edition; 2010; E-book (PDF) ISBN: 9788856829198.

12. Bovenzi FM. Ospedale per intensità di cura: scegliere leggero un compito pesante. G Ital Cardiol. 2011;12(1):21-2.

13. Ronco C, Antonelli M, Capasso G, De Gaudio R, Fiaccadori E, Lorini L, Mancini E, Monti G, Morabito S, Nalesso F, Piccinni P, Ricci Z, Romagnoli S, Santoro A. Italian Critical Care Nephrology Board Nomenclatura per le terapie di supporto durante danno renale acuto. G Ital Nefrol. 2015;32(2):1-26.

14. Ricci Z, Romagnoli S, Ronco C. Renal replacement therapy. F1000Research. 2016;103:1-13.

15. Villa G, Ricci Z, Ronco C. Renal replacement therapy. Crit Care Clin. 2015;31:839-48.

16. Godden J, Spexarth F, Dahlgren M. Standardization of continuous renalreplacement therapy fluids using a commercial product. Am J Health-Syst Pharm. 2012;69:786-93.

17. Gattas DJ, Rajbhandari D, Bradford C, Buhr H, Lo S, Bellomo R. A randomized controlled trial of regional citrate versus regional heparin anticoagulation for continuous renal replacement therapy in critically ill adults. Crit Care Med. 2015;43(8):1622-9.

Ready to submit your research? Choose BMC and benefit from:

- fast, convenient online submission

- thorough peer review by experienced researchers in your field

- rapid publication on acceptance

- support for research data, including large and complex data types

- gold Open Access which fosters wider collaboration and increased citations

- maximum visibility for your research: over $100 \mathrm{M}$ website views per year

At BMC, research is always in progress.

Learn more biomedcentral.com/submissions 